\title{
The Influence of Preeclampsia, Advanced Maternal Age and Maternal Obesity in Neonatal Outcomes Among Women with Gestational Diabetes
}

\section{A influência da pré-eclâmpsia, idade materna avançada e obesidade materna em desfechos neonatais entre mulheres com diabetes gestacional}

\author{
Joana Sousa Nunes ${ }^{1,2}$ Rita Ladeiras ${ }^{1}$ Luísa Machado ${ }^{1,2}$ Diana Coelho ${ }^{1,2(0)}$ Carla Duarte ${ }^{1,2(0)}$ \\ José Manuel Furtado ${ }^{1,2}$ (1)
}

1 Obstetrics \& Gynecology Department, Senhora da Oliveira Hospital, Guimarães, Portugal

2 Obstetrics \& Gynecology Department, Faculty of Medicine, Minho University, Braga, Portugal

Address for correspondence Joana Sousa Nunes, MD, Rua dos Cutileiros, 114, Creixomil, Guimarães, 4835-044, Portugal (e-mail: joananunes@hospitaldeguimaraes.min-saude.pt).

Rev Bras Ginecol Obstet 2020;42(10):607-613.

\begin{abstract}
Keywords

- gestational diabetes

- advanced maternal age

- maternal obesity

- preeclampsia

- neonatal outcomes

Objective The present study aims to analyze adverse fetal or neonatal outcomes in women with gestational diabetes, including fetal death, preterm deliveries, birthweight, neonatal morbidity and mortality, as well as the synergic effect of concomitant pregnancy risk factors and poor obstetric outcomes, as advanced maternal age, maternal obesity and pre-eclampsia in their worsening.

Methods The present cohort retrospective study included all pregnant women with gestational diabetes, with surveillance and childbirth at the Hospital da Senhora da Oliveira during the years of 2017 and 2018. The data were collected from the medical electronic records registered in health informatic programs Sclinico and Obscare, and statistical simple and multivariate analysis was done using IBM SPSS Statistics.

Results The study participants included 301 pregnant women that contributed to $7.36 \%$ of the total institution childbirths of the same years, in a total of 300 live births. It was analyzed the influence of pre-eclampsia coexistence in neonatal morbidity $(p=0.004)$, in the occurrence of newborns of low and very low birthweight $(p<0.01)$ and in preterm deliveries $(p<0.01)$. The influence of maternal obesity $(p=0.270 ; p=0.992 ; p=0.684)$ and of advanced maternal age in these 3 outcomes was also analyzed $(p=0,806 ; p=0.879$; $p=0.985)$.Using a multivariate analysis, the only models with statistic significance to predict the three neonatal outcomes included only pre-eclampsia $(p=0.04 ; p<0.01 ; p<0.01)$. Conclusion Only coexistence of pre-eclampsia showed an association with adverse neonatal outcomes (neonatal morbidity, newborns of low and very low birthweight and preterm deliveries) and can be used as a predictor of them in women with gestational diabetes.
\end{abstract}

received

January 7, 2020

accepted

March 10, 2020
DOI https://doi.org/

10.1055/s-0040-1710300. ISSN 0100-7203.
Copyright $\odot 2020$ by Thieme Revinter

Publicações Ltda, Rio de Janeiro, Brazil
License terms

(c) (i) 


\section{Resumo}

\section{Palavras-chave}

- diabetes gestacional

- idade materna avançada

- obesidade materna

- pré-eclâmpsia

- desfechos neonatais
Objetivo O presente estudo tem como objetivo analisar desfechos fetais ou neonatais adversos em mulheres com diabetes gestacional, incluindo morte fetal, partos prematuros, peso ao nascimento, morbilidade neonatal e mortalidade, bem como o efeito sinérgico de fatores de risco e maus desfechos concomitantes da gravidez, como idade materna avançada, obesidade materna e pré-eclâmpsia no seu agravamento.

Métodos $\mathrm{O}$ presente estudo retrospetivo de coorte incluiu todas as gestantes com diabetes gestacional, com vigilância e parto no Hospital da Senhora da Oliveira durante 2017 e 2018. Os dados foram obtidos dos registos clínicos eletrónicos dos programas informáticos de saúde Sclinico e Obscare, e a análise estatística simples e multivariada foi feita utilizando o IBM SPSS Statistics.

Resultados Os participantes do estudo incluíram 301 gestantes que contribuíram para $7,36 \%$ do total de partos da instituição, num total de 300 nados vivos. Foi analisada a influência da coexistência de pré-eclâmpsia na morbilidade neonatal $(p=0,004)$, na ocorrência de recém-nascidos de baixo e muito baixo peso ao nascimento $(p<0,01)$ e em partos prematuros $(p<0,01)$. Também foi analisada a influência da obesidade materna $(p=0,270 ; p=0,992 ; p=0,684)$ e da idade materna avançada nesses 3 desfechos $(p=0,806 ; p=0,879 ; p=0.985)$.Usando uma análise multivariada, os únicos modelos com significância estatística para predizer os três desfechos neonatais incluíram apenas a pré-eclâmpsia $(p=0,04 ; p<0,01 ; p<0,01)$.

Conclusão Apenas a coexistência de pré-eclâmpsia mostrou associação com desfechos neonatais adversos (morbilidade neonatal, recém-nascidos de baixo e muito baixo peso e partos prematuros) e pode ser utilizada como preditor destes em mulheres com diabetes gestacional.

\section{Introduction}

Gestational diabetes is a type of diabetes defined as any degree of glucose intolerance with onset or first recognition during pregnancy, after excluding women with previous diabetes. It usually constitutes $\sim 90 \%$ of all diabetes complicated pregnancies and it is one of the most frequent complications during pregnancy. A gradual increase in its prevalence has been observed worldwide. According to some authors, this increment was due to increasing rates of maternal obesity, which is not consensual among others. The global prevalence of gestational diabetes stands nowadays between 1 and 22\% and varies from country to country, depending on the genetic background, diagnostic methods employed and environmental factors. - Box 1 shows

Box 1 Common risk factors that may contribute to the increase of gestational diabetes

Common risk factors that may contribute to the increase of gestational diabetes

Previous diagnosis of gestational diabetes

Previous poor obstetric outcomes

Previous macrosomia

Advanced maternal age

Increasing prevalence of obesity

Polycystic ovarian syndrome

Family history of diabetes

Modern lifestyle with reduced physical activity and changed dietary habits

Smoking some of the common risk factors that may contribute to this increase. There is a higher risk of multiple maternal, fetal and neonatal adverse outcomes due to gestational diabetes. Considering some studies, body mass index (BMI) and maternal age showed to have the heaviest impact on pregnancy outcomes in women with gestational diabetes. ${ }^{1-37}$

Pregnancy at advanced maternal age has become more common in both developed and developing countries over the last decades. Advanced maternal age is considered to be $\geq 35$ years, being very advanced maternal age considered to be $\geq 40$ or 45 years. Advanced maternal age is an independent risk factor for gestational diabetes and early onset pre-eclampsia and is a known risk factor for other maternal and fetal adverse outcomes, such as miscarriage and ectopic pregnancy. Nevertheless, the correlation between advanced maternal age and adverse neonatal outcomes is still a matter of controversy in several studies. $^{1-37}$

The number of obese pregnant women, individuals with $\mathrm{BMI} \geq 30.0 \mathrm{~kg} / \mathrm{m} 2$, is increasing over time. ${ }^{5,12,18}$ Pregestational BMI is a risk factor for the development of maternal and perinatal complications. ${ }^{24,27}$ In the clinical practice, obesity and gestational diabetes commonly coexist and it is controversial which one the two conditions (gestational diabetes or maternal obesity) is more strongly associated with risk for adverse maternal and neonatal outcomes. ${ }^{10,13,19}$ Considering some authors, it seems that obese women with gestational diabetes have an increased risk of adverse outcomes compared with diabetic nonobese women, but more scientific evidence is necessary. ${ }^{23,35,36}$ 
Pre-eclampsia is one of the major pathologies in pregnancy and is a major health issue for women and their descendants worldwide. ${ }^{17,34}$ This disease is characterized by hypertension developing in pregnancy associated with new-onset proteinuria or other end-organ dysfunctions. ${ }^{34}$ According to some studies, pre-eclampsia complicates between 2 and $5 \%$ of all pregnancies. ${ }^{34}$ This disease seems to raise the risk of some important adverse pregnancy outcomes, raising morbidity and mortality not only in pregnant women but probably also in their offspring. ${ }^{17,34}$

It remains unclear whether the combination of gestational diabetes and other pregnancy risk factors and poor obstetric outcomes, such as advanced maternal age, maternal obesity and pre-eclampsia, represents a synergic risk in pregnancy, and whether the diagnosis and treatment of gestational diabetes among these women modifies this risk. So, it seems crucial to examine the results of current clinical care and assess if this care is sufficient or if it needs to be changed. The purpose of the present study was to analyze adverse fetal or neonatal outcomes of women with gestational diabetes, measured by fetal death, presence of preterm deliveries, birthweight, neonatal morbidity and neonatal death, as well as the synergic effect of concomitant pregnancy risk factors and poor obstetric outcomes, as advanced maternal age, maternal obesity and pre-eclampsia in the worsening of these outcomes.

\section{Methods}

\section{Identification of the Patients and Setting of Study}

This is a retrospective cohort study focusing on adverse fetal and neonatal outcomes of women with gestational diabetes whose pregnancy surveillance and childbirth took place at the Hospital da Senhora da Oliveira (HSO, in the Portuguese acronym), a tertiary center, during the years of 2017 and 2018. The data were collected from the medical records registered in HSO's health informatic programs Sclinico and Obscare. These programs contain data on all births in the mentioned hospital, including information on diagnosis, procedures, interventions, deliveries and newborns, as well as hospital outpatient care. Using these medical records, the following data were retrieved and analyzed: the incidence of gestational diabetes among all the deliveries occurred in 2018 in the HSO; as well as, among the women with gestational diabetes: maternal age, coexistence of preeclampsia, maternal BMI, gestational age and preterm deliveries, onset of labor (spontaneous or induced), mode of birth (normal birth, instrumental birth or cesarean), gender of the newborn, birthweight, fetal death, admission in a neonatal intensive care unit, neonatal morbidity and mortality.

\section{Variables Description}

Advanced maternal age was defined as maternal age $\geq 35$ years old and maternal obesity as a BMI $\geq 30 \mathrm{~kg} / \mathrm{m}^{2}$, using the pregestational weight of each pregnant woman for the ratio between weight and height squared. Preeclampsia was defined by hypertension (arterial pressure $\geq 140 / 90 \mathrm{mmHg}$ ) developing in pregnancy associated with new-onset proteinuria (protein to creatinine ratio in occasional urine $\geq 0,30$ or proteinuria in $24 \mathrm{~h}$ urine $\geq 300 \mathrm{mg}$ ) or other end-organ dysfunctions. Fetal death was defined as death in the gestational period. Neonatal mortality was defined as death in the neonatal period (from childbirth up to 28 days postpartum), and neonatal morbidity included pathological diagnosis in the same period, being them respiratory distress, metabolic acidosis, hypoxic-ischemic encephalopathy, hypoglycemia, hyperbilirubinemia, low Apgar scores at the $1^{\text {st }}$ and $5^{\text {th }}$ minutes of life, and congenital anomalies in the neonatal period. Birthweight was divided into 3 different categories: normal if $\geq 2500 \mathrm{~g}$, low if $<2500 \mathrm{~g}$ but $\geq 1500 \mathrm{~g}$, and very low if $<1500 \mathrm{~g}$. Preterm deliveries were defined by the gestational age on the moment of birth $<37$ weeks of gestation.

\section{Statistical Analysis}

The data were analyzed using IBM SPSS Statistics for Windows, Version 26.0 (IBM Corp., Armonk, NY, USA). A descriptive statistic was used to describe some of the most important variables, as maternal age, gestational age and birthweight. To verify the distribution of each variable, the Shapiro-Wilk normality test was used, more appropriated for the size of the studied sample. A simple analysis with linear regression was first done to compare each one of the variables with the studied outcomes. The independent sample $t$-test and the Mann-Whitney U-test were used to compare the means of continuous and categoric variables. To analyze the influence of a categoric variable in another categoric variable, the chi-squared test was used. Afterwards, a multivariate analysis was performed to assess the concomitance of maternal risk factors in neonatal outcomes, using a multiple regression. A p-value $<0.05$ was considered statistically significant, and a $95 \%$ confidence inter$\operatorname{val}(\mathrm{CI})$ was used. Analysis of differences between groups, tables, circle charts and histograms were also executed, all created in IBM SPSS for Windows, Version 26.0 (IBM Corp., Armonk, NY, USA). The results are expressed in percentages, and the means, ranges and standard deviations (SDs) are reported when appropriate. The present investigation was approved by the hospital's ethics committee and authorized by the Board of Directors of the Hospital da Senhora da Oliveira.

\section{Results}

The present study included a total number of 301 unifetal pregnancies (146 from 2017 and 155 from 2018). It was decided to exclude the 8 cases of twin pregnancies ( 3 from 2018 and 5 from 2017) from these data, since twin pregnancies are from the beginning associated with worse outcomes, which could interfere with our results.

The women had a mean maternal age of $33,37 \pm 5,12$ years old, with a minimum of 18 years old and a maximum of 47 years old, and their pregnancies had a median of gestational age of $38,00 \pm 2,00$ weeks, with a minimum of 30 weeks and a maximum of 41 weeks of gestation. They contributed to 301 childbirths within a total number of 4089 childbirths that occurred in 2017 and 2018 (2036 in 2017 and 2053 in 2018) in the HSO, corresponding to 7,36\% of childbirths, and led to 31 cases $(10,30 \%)$ of preterm births ( $<37$ weeks). The onset of labor was mainly spontaneous 
610 The Influence of Preeclampsia, Advanced Maternal Age and Maternal Obesity in Neonatal Nunes et al.

(56.10\%) and it was normal in about half of the cases (54.15\%). These 301 childibirths resulted in 300 live births (99.70\%) and 1 case of fetal death and stillbirth (0.30\%). There were no cases of neonatal mortality and $6.30 \%$ of cases of neonatal morbidity. The birthweight of the newborns had a mean of 3,146.97 $\pm 500,66 \mathrm{~g}$, with a minimum of $990 \mathrm{~g}$ and a maximum of $4,645 \mathrm{~g}$, and there were almost $8 \%$ of newborns with low and very low birthweight. The description of the study participants and pregnancy and neonatal outcomes can be analyzed in - Table 1 .

Regarding maternal age, there were $45.20 \%$ of cases of advanced maternal age and $54.80 \%$ of maternal age $<35$ years. The incidence of neonatal morbidity, newborns with low and very low birthweight and of preterm deliveries was similar among both categories $(6.0 \%, 7.40 \%$ and $10.40 \%$ in pregnant women with advanced maternal age versus $6.70 \%$, $7.90 \%$ and $10.30 \%$ in pregnant women without advanced maternal age, respectively). The influence of the advanced maternal age in these three outcomes was analyzed ( $p=0.806 ; p=0.879 ; p=0.985$, respectively). It's possible to analyze the aforementioned results in -Table 2 .

Considering the coexistence of pre-eclampsia with gestational diabetes, there were $6 \%$ of cases in both conditions versus $94 \%$ with only gestational diabetes. The incidence of neonatal morbidity, newborns with low and very low birthweight and of preterm deliveries was higher in the first group $(22.20 \%, 33.30 \%$ and $61.10 \%$ in pregnant women with pre-eclampsia and gestational diabetes versus $5.30 \%, 6.00 \%$ and $7.10 \%$ in pregnant women with only gestational diabetes, respectively). The in-
Table 2 Influence of coexistence of advanced maternal age with gestational diabetes in neonatal morbidity, low and very low birthweight and incidence of preterm deliveries

Influence of coexistence of advanced maternal age with gestational diabetes

\begin{tabular}{llll}
\hline $\begin{array}{l}\text { Pregnancy and } \\
\begin{array}{l}\text { Neonatal } \\
\text { outcomes }\end{array}\end{array}$ & $\begin{array}{l}\text { Maternal Age } \\
<35 \text { years old }\end{array}$ & $\begin{array}{l}\text { Maternal Age } \\
\geq 35 \text { years old }\end{array}$ & p-value \\
\hline $\begin{array}{l}\text { Neonatal } \\
\text { Morbidity }\end{array}$ & $\begin{array}{l}154(93.30) \\
\begin{array}{l}11(6.70) \\
\text { Absence (\%) }\end{array}\end{array}$ & $\begin{array}{l}126(94.00) \\
8(6.00)\end{array}$ & 0.806 \\
$\begin{array}{l}\text { Presence (\%) } \\
\text { Birthweight }\end{array}$ & $152(92.10)$ & $125(92.60)$ & 0.879 \\
$\geq 2500 \mathrm{~g}(\%)$ & $13(7.90)$ & $10(7.40)$ & \\
$<2500 \mathrm{~g}(\%)$ & & $121(89.60)$ & 0.985 \\
$\begin{array}{l}\text { Deliveries } \\
\text { Term (\%) }\end{array}$ & $148(89.70)$ & $14(10.40)$ & \\
Preterm (\%) & $17(10.30)$ & & \\
\hline
\end{tabular}

fluence of pre-eclampsia in these 3 outcomes was analyzed ( $p=0.004 ; p<0.01 ; p<0.01$, respectively). It is possible to analyze the aforementioned results in - Table 3.

In respect to the coexistence of maternal obesity (BMI $\geq 30 \mathrm{~kg} / \mathrm{m} 2$ ) with gestational diabetes, there were $\sim 26 \%$ of cases in these conditions versus $74 \%$ of cases with just gestational diabetes. The incidence of neonatal morbidity and of preterm deliveries was higher in the first group (9.00\% and $11.50 \%$ versus $5.40 \%$ and $9.90 \%$, respectively). The

Table 1 Description of study participants and pregnancy and neonatal outcomes

\begin{tabular}{|c|c|}
\hline Characteristics & Number of cases - \% \\
\hline \multicolumn{2}{|l|}{ Maternal characteristics } \\
\hline $\begin{array}{l}\text { Number of pregnant women (unifetal pregnancies) } \\
\text { with gestational diabetes }\end{array}$ & $30-100$ \\
\hline Advanced maternal age: Presence versus Absence & 136 versus $165-45.20$ versus 54.80 \\
\hline Preeclampsia: Presence versus Absence & 18 versus $283-6$ versus 94 \\
\hline Maternal Obesity: Presence versus Absence (missings) & 77 versus $223(1)-25.60$ versus $74.10(0.30)$ \\
\hline \multicolumn{2}{|l|}{ Pregnancy outcomes } \\
\hline $\begin{array}{l}\text { Onset of labor: Spontaneous versus } \\
\text { Induced versus Absence (missings) }\end{array}$ & $\begin{array}{l}169 \text { versus } 95 \text { versus } 35(2)-56.10 \text { versus } \\
31.60 \text { versus } 11.60(0-70)\end{array}$ \\
\hline $\begin{array}{l}\text { Type of labor: Normal versus Instrumental } \\
\text { versus Cesarean section (missings) }\end{array}$ & $\begin{array}{l}163 \text { versus } 45 \text { versus } 89(4)-54.15 \text { versus } \\
14.95 \text { versus } 29.57(1.33)\end{array}$ \\
\hline $\begin{array}{l}\text { Number of unifetal deliveries among all the } 2017 \text { and } 2018 \\
\text { deliveries in the mentioned hospital }\end{array}$ & $301 / 4,089-7.36$ \\
\hline Preterm deliveries versus Term deliveries (missings) & 31 versus $269(1)-10.30$ versus $89.40(0.30)$ \\
\hline \multicolumn{2}{|l|}{ Perinatal and neonatal outcomes } \\
\hline Live births versus Fetal deaths and stillbirths & 300 versus $1-99.70$ versus 0.30 \\
\hline Male newborns versus Female newborns & 165 versus $135-55$ versus 45 \\
\hline Birthweight: Normal versus Low versus Very low & 277 versus 20 versus $3-92.30$ versus 6.70 versus 1 \\
\hline Neonatal mortality: Presence versus Absence & 0 versus $300-0$ versus 100 \\
\hline Neonatal morbidity: Presence versus Absence (missings) & 19 versus $280(1)-6.30$ versus $93.30(0.30)$ \\
\hline Admission in a neonatal intensive care unit: Presence versus Absence & 17 versus $283-5.70$ versus 94.30 \\
\hline
\end{tabular}


Table 3 Influence of pre-eclampsia coexistence with gestational diabetes in neonatal morbidity, low and very low birthweight and incidence of preterm deliveries

Influence of coexistence of preeclampsia with gestational diabetes

\begin{tabular}{llll}
\hline $\begin{array}{l}\text { Pregnancy and } \\
\text { Neonatal } \\
\text { outcomes }\end{array}$ & $\begin{array}{l}\text { Without } \\
\text { preeclampsia }\end{array}$ & $\begin{array}{l}\text { With } \\
\text { preeclampsia }\end{array}$ & p-value \\
\hline $\begin{array}{l}\text { Neonatal } \\
\text { Morbidity }\end{array}$ & $266(94.70)$ & $14(77.80)$ & 0.004 \\
$\begin{array}{l}\text { Absence (\%) } \\
\text { Presence (\%) }\end{array}$ & $4(22.20)$ & \\
Birthweight & $265(94.00)$ & $12(66.70)$ & $<0.01$ \\
$\geq 2500 \mathrm{~g}(\%)$ & $17(6.00)$ & $6(33.30)$ & \\
$<2500 \mathrm{~g}(\%)$ & & & \\
$\begin{array}{l}\text { Deliveries } \\
\text { Term (\%) }\end{array}$ & $262(92.90)$ & $7(38.90)$ & $<0.01$ \\
Preterm (\%) & $20(7.10)$ & $11(61.10)$ & \\
\hline
\end{tabular}

incidence of newborns with low and very low birthweight was similar between both categories $(7.70 \%$ versus $7.70 \%$, respectively). The influence of maternal obesity in these three outcomes was analyzed $(p=0.270 ; p=0.992$; $p=0.684$, respectively). It is possible to analyze the aforementioned results in - Table 4 .

A multivariate analysis was performed to assess the concomitance of maternal risk factors in neonatal outcomes, using a multiple regression. In what concerns to the prevision of the outcome neonatal morbidity, the only model with statistic significance was the model including only preeclampsia: [F $\left.(1.297)=8.274 ; p<0.004 ; r^{2}=0.28\right]$. A $p$-value $=0.934$ and $p=0.530$ were obtained for models including 2 variables (pre-eclampsia and advanced maternal age) and including 3 variables (pre-eclampsia, advanced maternal age and maternal obesity), respectively. In what concerns to the prevision of newborns of low and very low birthweight, the only model with statistic significance was the model including only preeclampsia: $\left[\mathrm{F}(1.298)=26.761 ; p<0.01 ; r^{2}=0.084\right]$. A $\mathrm{p}$-value $=0.474$ and $p=0.686$ were obtained for models including two variables

Table 4 Influence of maternal obesity coexistence with gestational diabetes in neonatal morbidity, low and very low birthweight and incidence of preterm deliveries

Influence of coexistence of maternal obesity with gestational diabetes

\begin{tabular}{llll}
\hline $\begin{array}{l}\text { Pregnancy and } \\
\text { Neonatal } \\
\text { outcomes }\end{array}$ & $\begin{array}{l}\text { Without } \\
\text { maternal } \\
\text { obesity }\end{array}$ & $\begin{array}{l}\text { With } \\
\text { maternal } \\
\text { obesity }\end{array}$ & p-value \\
\hline $\begin{array}{l}\text { Neonatal Morbidity } \\
\text { Absence (\%) }\end{array}$ & $\begin{array}{l}209(94.60) \\
12(5.40)\end{array}$ & $\begin{array}{l}71(91.00) \\
7(9.00)\end{array}$ & 0.270 \\
$\begin{array}{l}\text { Presence (\%) } \\
\text { Birthweight }\end{array}$ & $205(92.30)$ & $72(92.30)$ & 0.992 \\
$\geq 2500 \mathrm{~g}(\%)$ & $17(7.70)$ & $6(7.70)$ & \\
$<2500 \mathrm{~g}(\%)$ & & & \\
$\begin{array}{l}\text { Deliveries } \\
\text { Term (\%) }\end{array}$ & $200(90.10)$ & $69(88.50)$ & 0.684 \\
Preterm (\%) & $22(9.90)$ & $9(11.50)$ & \\
\hline
\end{tabular}

(pre-eclampsia and advanced maternal age) and including 3 variables (pre-eclampsia, advanced maternal age and maternal obesity), respectively. In what concerns to the prevision of the outcome of preterm deliveries, the only model with statistic significance was the model including only preeclampsia: [F $\left.(1.298)=64.364 ; p<0,01 ; r^{2}=0.183\right]$. A $p$-value $=0.340$ and $p=0.312$ were obtained for models including two variables (pre-eclampsia and advanced maternal age) and including 3 variables (pre-eclampsia, advanced maternal age and maternal obesity), respectively.

\section{Discussion}

As our results showed, the current literature also demonstrated that women with gestational diabetes are at risk of both maternal, fetal and neonatal adverse outcomes, including pre-eclampsia and eclampsia (8-fold raise), increased risk of preterm birth, higher need for labor induction, caesarean section, stillbirths, macrosomia, full term low weight infants, newborns large for gestational age, neonatal morbidity (namely hyperbilirubinemia and jaundice, respiratory distress and asphyxia, hypoglycemia and congenital malformations), increased need to admission in neonatal intensive care unit and neonatal death (5-fold raise). ${ }^{2,11,16}$ However, there are also some studies that do not share the same scientific opinion. Some authors stated that the prevalence of newborns large for gestational age, cesarean section and preterm deliveries in gestational diabetes was not elevated. ${ }^{1}$

The statistically significant influence of pre-eclampsia coexistence in women with gestational diabetes in the ocurrence of neonatal morbidity, newborns of low and very low birthweight and preterm deliveries was at some point expected, since preeclampsia is per se a severe obstetric pathology with severe well-known pregnancy outcomes in the literature revision, as mentioned by many investigators: newborns small for gestational age, preterm birth and 5 minute Apgar score $<7 .{ }^{17,34}$ Nevertheless, the verified absence of influence of maternal obesity and advanced maternal age in the same group of women in these 3 outcomes, was instead against most of the authors, who do not only point them as risk factors for gestational diabetes, but also in most studies as aggravating factors of its outcomes. Considering the findings of some authors, an increased maternal insulin resistance in pregnancies with obesity and gestational diabetes promote the placental growth and inhibit its efficiency, being this pathophysiological mechanism responsible for the adverse outcomes in pregnant obese women with gestational diabetes. ${ }^{26,35}$ According to other investigators, prepregnancy obesity increased the likelihood of neonatal hypoglycemia among infants of mothers with gestational diabetes. $^{13}$ In certain studies, the mentioned association will increase the risk for obstetric and neonatal complications, in particular preterm birth and infant birth weight above the $90^{\text {th }}$ percentile. ${ }^{23,36}$ Nevertheless, according to some other studies, obesity (without gestational diabetes) is more frequently associated with adverse perinatal outcomes (including births at $<33$ weeks of gestation, birthweight $>4000 \mathrm{~g}$ and low 5-minute Apgar scores) than the association of obesity and gestational diabetes or than gestational diabetes in nonobese 
mothers, and, so, it's at least so crucial to treat prepregancy obesity as to prevent gestational diabetes in future mothers. ${ }^{35}$ This same finding is concordant with the results of the present study, which showed that maternal obesity doesn't seem to be an aggravating factor of gestational diabetes, which could be explained by the greater number of prenatal visits and strict vigilance of women with gestational diabetes that should be enough to achieve a more rigorous diet and weight control, as already mentioned in the recent literature. ${ }^{2,4,11}$ In the same way, other authors considered advanced maternal age as a potential risk factor of gestational diabetes, as well as an aggravating factor of it, capable to raise the incidence of adverse outcomes for mothers, newborns and infants, as spontaneous late preterm deliveries, fetal growth restriction, small for gestational age infants and birthweight $<2500$ g. ${ }^{3,14,21}$ However, according to some authors, maternal age does not significantly influence birthweight. ${ }^{25}$ Despite the findings in the literature, the present study did not find advanced maternal age as an aggravating factor of gestational diabetes, which could be explained also by a more rigorous vigilance of these pregnant women.

It is proven by the findings of many studies that early screening, high utilization of prenatal visits and subsequent treatment of gestational diabetes to promote maternal-fetal health allows the adhesion to a more balanced diet and to a regular exercise program, which leads to a more strict weight reduction and better glycemic control in the 3 months prior to birth, with a consequent improvement of some known adverse outcomes, such as preterm deliveries, neonatal morbidity, infants requiring neonatal intensive care unit (NICU) admission or maternal risk for diabetes later in life., ${ }^{2,30}$ Therefore, the verification of maternal obesity and advanced maternal age as nonaggravating factors of gestational diabetes in the present study may be a proof of an adequate obstetric vigilance and strict metabolic control of the pregnant women with gestational diabetes in the present tertiary center.

Using the multivariate analysis, it was shown that only preeclampsia in women with gestational diabetes can be used to predict the three studied outcomes (neonatal morbidity, newborns of low and very low birthweight and preterm deliveries). Neither maternal obesity nor advanced maternal age are predictors of these neonatal outcomes in women with gestational diabetes. As mentioned above, the severity of this obstetric pathology can be a reasonable explanation.

As strengths of the study itself, it could be mentioned the good amount of information of the participants, as well as the outcomes evaluated. Moreover, the majority of the variables in the present study (maternal age, BMI, fetal death, birthweight, neonatal mortality) were objective parameters, not influenced by inter or intraobserver variability in their measurement. As limitations of the present study, it could be enumerated the retrospective character of the study instead of a prospective one and the selection of the study population from one single hospital, and not from many, which could be resolved by a multicenter study, possibly more representative, not only in respect to the number of pregnant women involved but also considering different settings and backgrounds of the population analyzed.

\section{Conclusion}

Although the coexistence of pre-eclampsia and gestational diabetes showed a statistically significant association with adverse neonatal outcomes, neither the association of advanced maternal age nor maternal obesity with gestational diabetes had a negative influence on these outcomes. Moreover, in a multivariate analysis, it was shown that only pre-eclampsia can be used to predict the neonatal outcomes (neonatal morbidity, newborns of low and very low birthweight and preterm deliveries) in women with gestational diabetes.

\section{Contributors}

All of the authors contributed with the project and data interpretation, the writing of the article, the critical review of the intellectual content, and with the final approval of the version to be published.

\section{Conflict of Interests}

The authors have no conflict of interests to declare.

\section{Acknowledgments}

I wish to thank all of those who contributed to the completion of this study, meaning families, friends, health professionals and the Board of Directors of Hospital da Senhora da Oliveira - Guimarães, EPE.

\section{References}

1 Stogianni A, Lendahls L, Landin-Olsson M, Thunander M. Obstetric and perinatal outcomes in pregnancies complicated by diabetes, and control pregnancies, in Kronoberg, Sweden. BMC Pregnancy Childbirth. 2019;19(01):159. Doi: 10.1186/s12884-019-2269-8

2 Bawah AT, Ngala RA, Alidu H, Seini MM, Wumbee JDK, Yeboah FA. Gestational diabetes mellitus and obstetric outcomes in a Ghanaian community. Pan Afr Med J. 2019;32:94. Doi: 10.11604/ pamj.2019.32.94.17334

3 Kahveci B, Melekoglu R, Evruke IC, Cetin C. The effect of advanced maternal age on perinatal outcomes in nulliparous singleton pregnancies. BMC Pregnancy Childbirth. 2018;18(01):343. Doi: 10.1186/s12884-018-1984-x

4 Ryan DK, Haddow L, Ramaesh A, Kelly R, Johns EC, Denison FC, et al. Early screening and treatment of gestational diabetes in high-risk women improves maternal and neonatal outcomes: A retrospective clinical audit. Diabetes Res Clin Pract. 2018; 144:294-301. Doi: 10.1016/j.diabres.2018.09.013

5 Bianchi C, de Gennaro G, Romano M, Aragona M, Battini L, Del Prato S, Bertolotto A, et al. Pre-pregnancy obesity, gestational diabetes or gestational weight gain: Which is the strongest predictor of pregnancy outcomes? Diabetes Res Clin Pract. 2018;144:286-293. Doi: 10.1016/j.diabres.2018.08.019

6 Domanski G, Lange AE, Ittermann T, Allenberg H, Spoo RA, Zygmunt M, Heckmann $M$, et al. Evaluation of neonatal and maternal morbidity in mothers with gestational diabetes: a population-based study. BMC Pregnancy Childbirth. 2018;18 (01):367. Doi: 10.1186/s12884-018-2005-9

7 Pintaudi B, Fresa R, Dalfrà M, Dodesini AR, Vitacolonna E, Tumminia A, et al; STRONG Study Collaborators. The risk stratification of adverse neonatal outcomes in women with gestational diabetes (STRONG) study. Acta Diabetol. 2018;55(12):1261-1273. Doi: 10.1007/s00592-018-1208-X

8 Shen J, Zhang Z, Chen K, Lu M, Qian Q, Liu P, et al. Prepregnancy obesity status and risks on pregnancy outcomes in Shanghai: A 
prospective cohort study. Medicine (Baltimore). 2018;97(40): e12670. Doi: 10.1097/MD.0000000000012670

9 Ding TT, Xiang J, Luo BR, Hu J. Relationship between the IADPSGcriteria-defined abnormal glucose values and adverse pregnancy outcomes among women having gestational diabetes mellitus: A retrospective cohort study. Medicine (Baltimore). 2018;97(43): e12920. Doi: 10.1097/MD.0000000000012920

10 Ramonienė G, Maleckienė L, Nadišauskienė RJ, Bartusevičiené E, Railité R, Mačiulevičiené R, Maleckas A. Maternal obesity and obstetric outcomes in a tertiary referral center. Medicina (Kaunas). 2017;53(02):109-113. Doi: 10.1016/j.medici.2017.03.003

11 Basri NI, Mahdy ZA, Ahmad S, Karim AKA, Shan LP, Manaf MRA, Ismail NAM. The World Health Organization (WHO) versus The International Association of Diabetes and Pregnancy Study Group (IADPSG) diagnostic criteria of gestational diabetes mellitus (GDM) and their associated maternal and neonatal outcomes. Horm Mol Biol Clin Investig. 2018;34(01):20170077. Doi: 10.1515/hmbci-2017-0077

12 Boudet-Berquier J, Salanave B, Desenclos JC, Castetbon K. Sociodemographic factors and pregnancy outcomes associated with prepregnancy obesity: effect modification of parity in the nationwide Epifane birth-cohort. BMC Pregnancy Childbirth. 2017;17 (01):273. Doi: 10.1186/s12884-017-1456-8

13 Collins K, Oehmen R, Mehta S. Effect of obesity on neonatal hypoglycaemia in mothers with gestational diabetes: A comparative study. Aust N Z J Obstet Gynaecol. 2018;58(03):291-297. Doi: 10.1111/ajo.12717

14 Fayed AA, Wahabi H, Mamdouh H, Kotb R, Esmaeil S. Demographic profile and pregnancy outcomes of adolescents and older mothers in Saudi Arabia: analysis from Riyadh Mother (RAHMA) and Baby cohort study. BMJ Open. 2017;7(09):e016501. Doi: 10.1136/bmjopen-2017-016501

15 Gonzalez-Ballano I, Saviron-Cornudella R, Esteban LM, Sanz G, Castán S. Pregestational body mass index, trimester-specific weight gain and total gestational weight gain: how do they influence perinatal outcomes? J Matern Fetal Neonatal Med. 2019:1-8. Doi: 10.1080/14767058.2019.1628942

16 Hosseini E, Janghorbani M. Systematic review and meta-analysis of diagnosing gestational diabetes mellitus with one-step or twostep approaches and associations with adverse pregnancy outcomes. Int J Gynaecol Obstet. 2018;143(02):137-144. Doi: 10.1002/ijgo.12644

17 Iacobelli S, Bonsante F, Robillard PY. Comparison of risk factors and perinatal outcomes in early onset and late onset preeclampsia: A cohort based study in Reunion Island. J Reprod Immunol. 2017;123:12-16. Doi: 10.1016/j.jri.2017.08.005

18 Zutshi A, Santhosh J, Sheikh J, Naeem F, Al-Hamedi Ahmed, Khan $\mathrm{S}$, Al-Said E. Implications of early pregnancy obesity on maternal, fetal and neonatal health: retrospective cohort study from Oman. Sultan Qaboos Univ Med J. 2018;18(01):e47-e53. Doi: 10.18295/ squmj.2018.18.01.008

19 Ju AC, Heyman MB, Garber AK, Wojcicki JM. Maternal obesity and risk of preterm birth and low birthweight in Hawaii PRAMS, 2000-2011. Matern Child Health J. 2018;22(06):893-902. Doi: 10.1007/s10995-018-2464-7

20 Lean SC, Derricott H, Jones RL, Heazell AEP. Advanced maternal age and adverse pregnancy outcomes: A systematic review and meta-analysis. PLoS One. 2017;12(10):e0186287. Doi: 10.1371/ journal.pone. 0186287

21 Marozio L, Picardo E, Filippini C, Mainolfi E, Berchialla P, Cavallo F, et al. Maternal age over 40 years and pregnancy outcome: a hospital-based survey. J Matern Fetal Neonatal Med. 2019;32(10): 1602-1608. Doi: 10.1080/14767058.2017.1410793

22 Longmore DK, Barr ELM, Lee IL, Barzi F, Kirkwood M, Whitbread C, et al; PANDORA study research team. Maternal body mass index, excess gestational weight gain, and diabetes are positively asso- ciated with neonatal adiposity in the Pregnancy and Neonatal Diabetes Outcomes in Remote Australia (PANDORA) study. Pediatr Obes. 2019;14(04):e12490. Doi: 10.1111/ijpo.12490

23 Huet J, Beucher G, Rod A, Morello R, Dreyfus M. Joint impact of gestational diabetes and obesity on perinatal outcomes. J Gynecol Obstet Hum Reprod. 2018;47(09):469-476. Doi: 10.1016/j. jogoh.2018.08.003

24 Poprzeczny AJ, Louise J, Deussen AR, Dodd JM. The mediating effects of gestational diabetes on fetal growth and adiposity in women who are overweight and obese: secondary analysis of the LIMIT randomised trial. BJOG. 2018;125(12):1558-1566. Doi: 10.1111/1471-0528.15288

25 Spada E, Chiossi G, Coscia A, Monari F, Facchinetti F. Effect of maternal age, height, BMI and ethnicity on birth weight: an Italian multicenter study. J Perinat Med. 2018;46(09):1016-1021. Doi: 10.1515/jpm-2017-0102

26 Tanaka K, Yamada K, Matsushima M, Izawa T, Furukawa S, Kobayashi $\mathrm{Y}$, Iwashita $\mathrm{M}$, et al. Increased maternal insulin resistance promotes placental growth and decreases placental efficiency in pregnancies with obesity and gestational diabetes mellitus. J Obstet Gynaecol Res. 2018;44(01):74-80. Doi: 10.1111/jog.13474

27 Zhao R, Xu L, Wu ML, Huang SH, Cao XJ. Maternal pre-pregnancy body mass index, gestational weight gain influence birth weight. Women Birth. 2018;31(01):e20-e25. Doi: 10.1016/j.wombi.2017.06.003

28 Sugiyama MS, Cash HL, Roseveare C, Reklai R, Basilius K, Madraisau $\mathrm{S}$. Assessment of gestational diabetes and associated risk factors and outcomes in the Pacific Island Nation of Palau. Matern Child Health J. 2017;21(10):1961-1966. Doi: 10.1007/s10995017-2313-0

29 Vinturache AE, Chaput KH, Tough SC. Pre-pregnancy body mass index (BMI) and macrosomia in a Canadian birth cohort. J Matern Fetal Neonatal Med. 2017;30(01):109-116. Doi: 10.3109/ 14767058.2016.1163679

30 Carter EB, Tuuli MG, Odibo AO, Macones GA, Cahill AG. Prenatal visit utilization and outcomes in pregnant women with type II and gestational diabetes. J Perinatol. 2017;37(02):122-126. Doi: 10.1038/jp.2016.175

31 Mariona FG. Perspectives in obesity and pregnancy. Womens Health (Lond). 2016;12(06):523-532. Doi: 10.1177/1745505716686101

32 McGillick EV, Lock MC, Orgeig S, Morrison JL. Maternal obesity mediated predisposition to respiratory complications at birth and in later life: understanding the implications of the obesogenic intrauterine environment. Paediatr Respir Rev. 2017;21:11-18. Doi: $10.1016 /$ j.prrv.2016.10.003

33 Billionnet C, Mitanchez D, Weill A, Nizard J, Alla F, Hartemann A, Jacqueminet $S$. Gestational diabetes and adverse perinatal outcomes from 716,152 births in France in 2012. Diabetologia. 2017; 60(04):636-644. Doi: 10.1007/s00125-017-4206-6

34 Shen M, Smith GN, Rodger M, White RR, Walker MC, Wen SW. Comparison of risk factors and outcomes of gestational hypertension and pre-eclampsia. PLoS One. 2017;12(04):e0175914. Doi: 10.1371/journal.pone.0175914

35 Blickstein I, Doyev R, Trojner Bregar A, Bržan Šimenc G, Verdenik I, Tul N. The effect of gestational diabetes, pre-gravid maternal obesity, and their combination ('diabesity') on outcomes of singleton gestations. J Matern Fetal Neonatal Med. 2018;31(05): 640-643. Doi: 10.1080/14767058.2017.1293030

36 Miao M, Dai M, Zhang Y, Sun F, Guo X, Sun G. Influence of maternal overweight, obesity and gestational weight gain on the perinatal outcomes in women with gestational diabetes mellitus. Sci Rep. 2017;7(01):305. Doi: 10.1038/s41598-017-00441-z

37 Filardi T, Tavaglione F, Di Stasio M, Fazio V, Lenzi A, Morano S. Impact of risk factors for gestational diabetes (GDM) on pregnancy outcomes in women with GDM. J Endocrinol Invest. 2018;41 (06):671-676. Doi: 10.1007/s40618-017-0791-y 